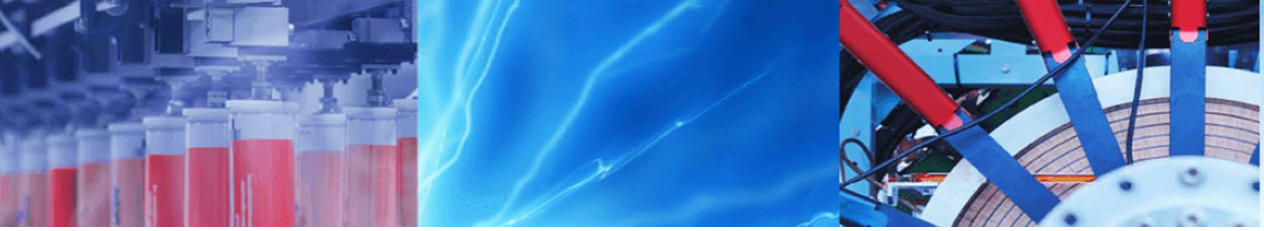

Research Article

\title{
Design and study of mini wind tunnel for microsystems fluid interaction under low Reynolds number flows
}

\author{
K. P. Neriya Hegade ${ }^{1} \cdot$ R. Natalia ${ }^{1}$ - B. Wehba ${ }^{1}$ A. Mittal ${ }^{1}$ 'R. B. Bhat ${ }^{1} \cdot$ M. Packirisamy $^{1}$ (I)
}

Received: 4 November 2019 / Accepted: 26 March 2020 / Published online: 8 April 2020

(c) Springer Nature Switzerland AG 2020

\begin{abstract}
This paper discusses details of design and fabrication of a simple open-loop modular mini wind tunnel for studying fluid microstructure interaction under low Reynolds number. A simple open-loop modular mini wind tunnel was designed and built after examining various design possibilities. The mini wind tunnel consists of five basic sections, namely wideangle diffuser, settling chamber, contraction section, test section and exit diffuser. The settling chamber consists of flow straighter made from array of circular tubes. Mini wind tunnel is powered by incorporating a fan which provides air flow with $\operatorname{Re}<1500$. Flow behavior inside the mini wind tunnel, particularly test section, was investigated by performing flow simulation using COMSOL finite element modeling. Additionally, smoke experiments confirm streamline flow inside the test section. Fluid interaction of microcantilevers was investigated using the designed mini wind tunnel. Polydimethylsiloxane microcantilever beam of different aspect ratios was fabricated and tested for airflow sensing applications. Microcantilevers are placed normal to fluid flow and steady tip deflection.
\end{abstract}

Keywords Fluid microstructure interaction · Flow modeling · Flow sensor · Low Reynolds number flows · Microcantilever $\cdot$ Mini wind tunnel

\section{Introduction}

A small-scale wind tunnel is in the millimeter range to determine fundamental characteristic such as force and drag on a design of choice. However, the forces at the millimeter level cannot be measured in large wind tunnels. Therefore, mini wind tunnel is needed to test devices such as microcantilevers as shown in Fig. 1, micro-sensors, micro-electromechanical system, etc., to determine the characteristics of the microstructure. The design of miniature wind tunnel is not readily available, and hence, there is importance of designing, fabricating and testing in building successful microsystems. Over the years, wind tunnel has been widely used to study the structure interaction with air. Many interesting studies were performed using wind tunnel. Kuo et al. [1] studied the effect of highrise buildings to wind direction and velocity.

Series of high-rise building makes a virtual street canyon. Such street canyons push shorter buildings and the pedestrians in the street to a position of vulnerability when there is a strong wind. These artificial channeling will increase the velocity and change the natural direction of the flow. This group studied the effect of street width, podium height and wind direction using a closed loop

Electronic supplementary material The online version of this article (https://doi.org/10.1007/s42452-020-2602-x) contains supplementary material, which is available to authorized users.

$\triangle$ M. Packirisamy, pmuthu@alcor.concordia.ca; K. P. Neriya Hegade, k_neriya@encs.concordia.ca; R. Natalia, ravi_24_nat@hotmail.com; B.Wehba, basel-wehba@hotmail.com; A. Mittal, mittal_aditya@outlook.com; R. B. Bhat, rama.bhat@concordia.ca| ${ }^{1}$ Optical Bio-Microsystems Laboratory, Department of Mechanical and Industrial Engineering, Concordia University, EV4-149, 1515 St. Catherine St. West, EV13.235, Montreal, QC H3G 1M8, Canada. 


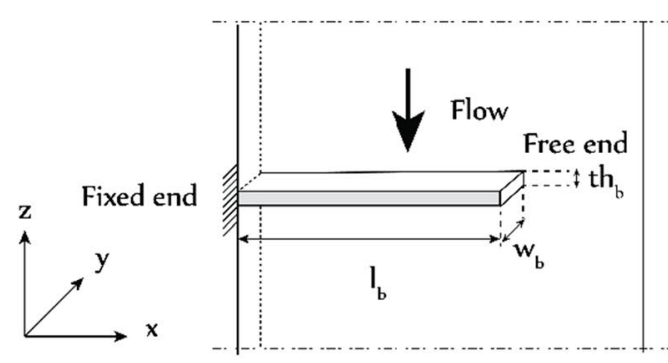

(a)

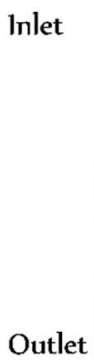

Outlet

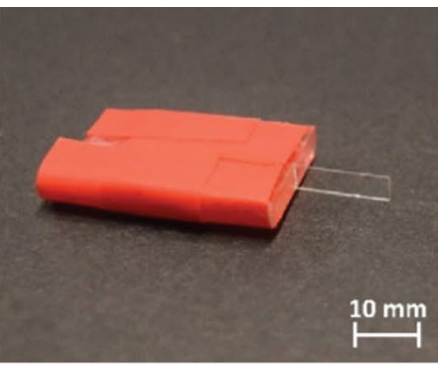

(b)

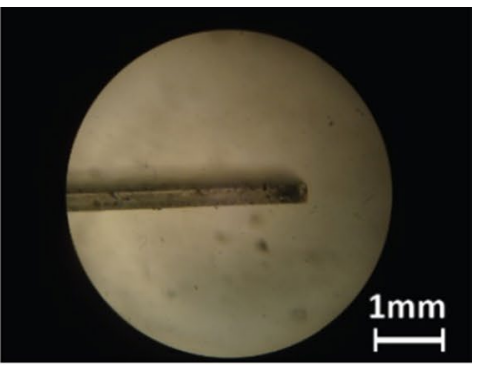

(c)

Fig. 1 a Schematic of microcantilever subjected to flow $\mathbf{b}$ A microcantilever beam $(4 \times 12 \times 0.24 \mathrm{~mm})$ attached to PDMS base and $\mathbf{c}$ Microcantilever tip under microscope

blower wind tunnel. The wind tunnel used for the study consists of two test section separated by a rectangular flow channel. The maximum wind speed of $30 \mathrm{~m} / \mathrm{s}$ was used for the study. Watanabe et al. [2] studied paper fluttering in wind tunnel to study the phenomenon of paper fluttering. Paper fluttering is common phenomenon in printing presses while folding the papers using rollers. A blower type of wind tunnel is used in this study with test cross section area of 1 square meter. The wind velocity used for the study is $25 \mathrm{~m} / \mathrm{s}$. Yu et al. [3] used wind tunnel to study the phenomena of parachute inflation. A steady velocity of $18 \mathrm{~m} / \mathrm{s}$ was used to inflate the parachute. This study was primarily done to design parachute that takes less time to inflate and gives great control for the rider. Bastankhah et al. [4] performed wind tunnel experiment to finalize the turbine design. Turbulent flow was used for the study. Closed loop wind tunnel was used with test section dimension of $28 \mathrm{~m}$ long, $2.5 \mathrm{~m}$ wide and a height of $2.25 \mathrm{~m}$. A steady constant velocity of $4.88 \mathrm{~m} / \mathrm{s}$ was used for the study with Reynolds number in the range of 8000 to 37,000 . Howell et al. [5] used an open-loop wind tunnel with test section dimensions of $3 \mathrm{~m} \times 1.2 \mathrm{~m} 1.2 \mathrm{~m}$ to study vertical line wind turbine.

To study fluid interaction of microstructure at low Reynolds number flow, a mini wind tunnel is necessary which facilitates testing of small structures. Where test structures can be kept inside the test section using an opening. The opening inside the test section to place test structure should be carefully designed. It should be large enough to place the test structure inside the test section, yet it should not disturb the flow pattern. After examining wind tunnels used for various studies, simple open-loop mini wind tunnel design was chosen to build. Using the fundamentals of fluid dynamics, dimensions of each part of the mini wind tunnel were finalized. Flow simulation inside the mini wind tunnel was carried out using Laminar flow module in COMOSOL Multiphysics. Results from simulations were satisfactory since flow inside the test section is well within laminar flow range. Experimentally, smoke test was done to see the streamline flow within the test section. Later PDMS microcantilever results ensured the mini wind tunnel design can be used to test fluid interaction of any new microstructures.

\section{Design considerations}

Wind tunnel is a tunnel like structure that allows testing models before their respective usage. Wind tunnel has adapted over decades; however, its primitive structure follows the same design rules. There are numerous configurations of wind tunnel based on size, flow velocity flow type and flow cycle. The primary design choice is based on the test object. Other important design considerations are test section, Reynolds number, flow type and flow cycle [6]. The present mini wind tunnel is designed for studying fluid interaction of structure with maximum size of $15 \mathrm{~mm}^{2}$ under laminar flow.

Reynolds number is defined as the ratio between inertial force and viscous force [7]:

$\operatorname{Re}=\frac{D_{h} \times v}{v}$

where:

Re-Reynolds Number

$D_{h}$-Hydraulic diameter $(\mathrm{m})$

$v$-Kinematic Viscosity of Air $\left(\mathrm{m}^{2} / \mathrm{s}\right)$

$V$-Velocity of the fluid $(\mathrm{m} / \mathrm{s})$

The hydraulic diameter is given by Eq. (2) [7]:

$D_{h}=\frac{4 A}{P}$

where $A$ is the cross-sectional area of the test section and $P$ is the wetted perimeter. 
In general, Reynolds number is less than 2300 in laminar flow; hence, the Reynolds number inside test section is chosen to be 1500 , well within laminar flow range.

An open-loop cycle was chosen because open-loop wind tunnel is safe from temperature changes in the flow [8]. Size of the mini wind tunnel is very small as compared to size of the room. This facilitates continuous supply of air at room temperature, which is not possible in closed loop. In addition, an open-loop wind tunnel is free from flow disturbance at the inlet, as there is no re-entry of the flow as in the case of closed loop. Two types of flow are possible inside the wind tunnel. One is the suck-down, and the other is blow-down wind tunnel as shown in Fig. 2. The suck-down wind tunnel sucks the air inside the wind tunnel rather than blowing the air. This configuration is rarely used since the entry has to re-ingest the exit flow after it returns through outside [8] (Fig. 2a). Flow straighteners are necessary in this configuration since the flow returning is not consistent. The other configuration is the blow-down wind tunnel as shown in Fig. 2b. The blow-down wind tunnel is the most widely used wind tunnel for its simplicity and cost benefits. The inlet of the wind tunnel contains a wide-angle diffuser [8]. Usual diffusers in wind tunnels have only one diffuser at the exit where the flow leaves at an angle less than 5 degrees, but the blow-down wind tunnel is an exception. The blow-down wind tunnel has inlet diffuser angles exceeding 20 degrees. Wide-angle diffuser enables the flow to develop at shorter distance.

Based on all the design consideration a final decision of open-loop laminar flow, mini wind tunnel was made. The open-loop laminar flow mini wind tunnel is an assembly of five main sections, which all have an integral role for the flow. The main parts are the wide-angle diffuser, settling chamber, contraction section, test section, and exit diffuser. The wide-angle diffuser connected to the fan allows the flow to expand and decrease in velocity into the settling chamber. The settling chamber allows the fluid to straighten and is the region of the lowest velocity. The contraction section increases the velocity of the flow to get a uniform flow in the test section. The test section is the heart of the wind tunnel with the highest velocity, where the model is tested. Lastly, the diffuser slows down the fluid allowing it to exit the wind tunnel slowly to the outside atmosphere without disturbing the flow inside [8].

\section{Theoretical modeling of wind tunnel design}

The mini wind tunnel is an assembly of five main sections that all have an important role for the flow of the wind tunnel. The five parts are the wide-angle diffuser, settling chamber, contraction section, test section and exit diffuser, all in order from inlet to outlet, left to right as shown in Fig. 2b. The design of each part depends on each other through various design parameters that are outlined in this section. A micro-fan was used to power the mini wind tunnel. Modularity of the wind tunnel is achieved by replacing the micro-fan at the inlet. Similarly, the test section is replaceable in a modular fashion by loosening and tightening the correct cross section needed for a desired Reynolds number.

\subsection{Test section}

The test section is the most important part of the wind tunnel since it is where the test model is placed. The flow around the test model must not separate and continue without mixing. For the flow to be laminar and smooth, Reynolds number should be less than 2100 [9]. In this design, a Reynolds number of 1500 , which is well below this region, is examined. Test section has rectangular cross
Fig. 2 Two potential setups for open loop wind tunnel. a Suck-down wind tunnel, b Blow-down wind tunnel

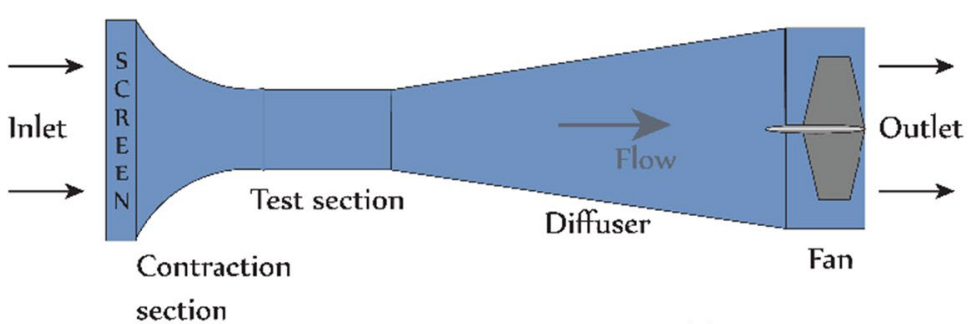

(a)

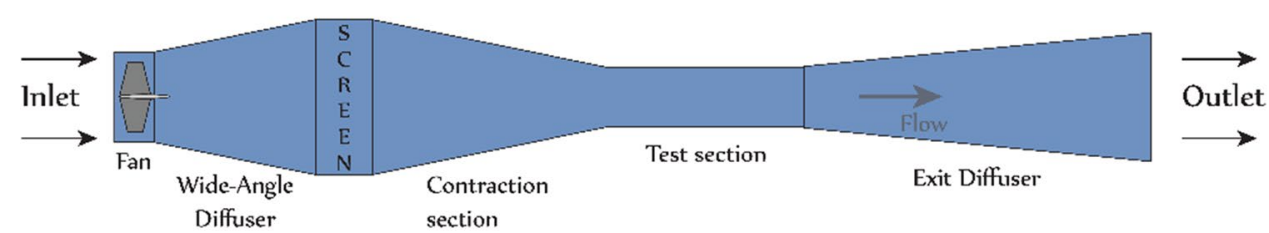

(b) 
section, and a common rule is that the width-to-height ratio of the cross section of the test chamber for small low speed wind tunnels should be approximately $\sqrt{2}$ [8]. Lastly, the area of the fan should be 2-3 times larger than the test section [10].

The dimension of the test section depends on the maximum size of the model that needs to be studied. For this design, maximum hydraulic diameter of $15 \mathrm{~mm}$ was selected as most of the microstructure size fall well below this size range.

Hydraulic diameter for rectangular cross section is given as

$D_{H, T S}=\frac{2 a b}{(a+b)}$

where $D_{H, T S} a$ and $b$ are hydraulic diameter, height and width of the test section, respectively

$15=\frac{2 a(a \sqrt{ } 2)}{(a+a \sqrt{ } 2)}$

Substituting $b=a \sqrt{2}$ and $D_{H}=15 \mathrm{~mm}$ in Eq. (3) gives $a$ and $b$ value as 12.84 and $18.16 \mathrm{~mm}$, respectively. They are adjusted as $18 \mathrm{~mm}$ and $12.5 \mathrm{~mm}$.

Flow out of the contraction becomes nearly uniform after a distance about 0.5 times the diameter of the test section inlet. Minimum length of the test section is determined by this factor [8]. However, to incorporate sensors (if required for a study) total length of $100 \mathrm{~mm}$ was chosen. This length makes test samples to be kept symmetrically at the middle of the test section which is $50 \mathrm{~mm}$ away from the inlet.

\subsection{Contraction section}

For wind tunnels that deal with turbulent flow, it is important to design the contraction following a fifth-degree polynomial for the flow not to separate [11]. However, for low-speed wind tunnel with laminar flow, constructing a fifth-degree polynomial cross section is not essential, and a circular or rectangular cross section will suffice. The two main constraints placed on the contraction are the area ratio and the length. The area ratio between the inlet and outlet for the contraction is a value between 6 and $9[8,12]$. The length of the contraction is approximately same as the inlet height of the contraction section [13]. A 45-degree corner fillet to reduce the separation of the fluid [13] is provided. The main purpose of the contraction is to increase the velocity of the fluid and to reduce the velocity fluctuation.

The inlet dimension of the contraction is $40 \times 48 \mathrm{~mm}$, and that of outlet which leads to the test section is
$18 \times 12.5 \mathrm{~mm}$. Inlet dimension of contraction is chosen as the one mentioned above because of the honeycomb structure present inside the settling chamber which is attached to the inlet of contraction section. Honeycomb structure used in the design is $11 \times 12$ array (height $\times$ width) of circular tube with diameter $3.5 \mathrm{~mm}$. In order to incorporate honeycomb structure and have spacing to install them, the dimension of settling chamber is chosen as $40 \times 48 \mathrm{~mm}$ which determines the inlet dimension of contraction section to be $40 \times 48 \mathrm{~mm}$. The area ratio (contraction ratio) resulting from chosen inlet dimension of the contraction section is 8.53 , which is within the design rule of 6-9. The length of the contraction is same as the inlet height of the contraction, however, and additional $20 \mathrm{~mm}$ is incorporated to subdue any effects resulting from settling chamber. Hence the length of the contraction $60 \mathrm{~mm}$.

\subsection{Settling chamber}

The settling chamber is a straight short portion of the wind tunnel where the cross section is the largest and is constant. The settling chamber contains screens and honeycomb structure to straighten the flow. The length of the settling chamber is 0.5 times the inlet diameter of the contraction section [10]. The settling chamber cross section is the same as that of the inlet of the contraction, $40 \times 48 \mathrm{~mm}$. Since the inlet of the contraction is not circular, the equivalent diameter is found by using the dimension of the cross section [9]:

$D_{\text {eq }}=\frac{1.265 \times a_{\mathrm{SC}}^{0.6} \times b_{\mathrm{SC}}^{0.6}}{\left(a_{\mathrm{SC}}+b_{\mathrm{SC}}\right)^{0.2}}$

where, $D_{\text {eq }}$-Equivalent diameter of the contraction section, $a_{\mathrm{sc}}$-Width of the settling chamber and $b_{\mathrm{sc}}$ - Height of the settling chamber. Equivalent diameter of contraction section is $48.21 \mathrm{~mm}$. Mehta and Bradshaw describe that the cell length of the settling chamber should be 6-8 times the diameter of the cell used in the honeycomb structure [8]. Here, we used 3.5-mm circular tube; setting settling chamber length as $25 \mathrm{~mm}$ satisfies both the conditions mentioned above. Although the same literature states there should be a spacing equivalent to 0.2 times the cross-sectional diameter of settling should be given between honeycomb structure and contractions section. However, $20 \mathrm{~mm}$ additional length considered while designing contraction section satisfies this condition

\subsection{Wide-angle diffuser}

The wide-angle diffuser is the section that is connected to the fan and is dependent on four main parameters: 
the area ratio, the diffuser angle, number of screens in the diffuser and drop coefficient of the screens [8]. The wide-angle diffuser has greater angle than usual diffusers with its cross-sectional area increasing very rapidly. The wide-angle diffuser is inserted at the beginning of the wind tunnel and has area ratio between 1 and 4 with an inlet area larger than that of the test section by a factor of 2 to 3 [10]. Ideally, the selection of the fan is axial, and the area ratio must be taken with respect to an inlet circular cross section. A $25-\mathrm{mm}$ diameter axial fan satisfies all the above requirements. The length of the diffuser is roughly the hydraulic diameter of the settling chamber, which is $45 \mathrm{~mm}$.

\subsection{Exit diffuser}

The exit diffuser is fitted downstream of the test section to allow the flow to leave slowly out. The angle of expansion is between 2 and 3 degrees, the area ratio is $2-3$ times larger than that of the inlet. There are designs without exit diffuser; however, those models suffer from flow instability in the test section. Exit diffuser is needed to further reduce the fluctuation of the velocity in the test section. The area ratio chosen for the exit diffuser is 1.54, and angle of expansion is 3 degrees. According to these constraints, the length is chosen to be $120 \mathrm{~mm}$.

\subsection{Assembly/fabrication}

The wind tunnel assembly is completed once all the five parts are designed and fabricated. The cross section, angles and lengths are summarized in Fig. 3 . The test section is of the prime importance because here the microstructure of interest will be kept and analyzed. Therefore, this section requires

additional design features such as openings to place test objects, sensors, etc. Hence two 10-mm diameter openings are made on the sidewalls for data acquisition and monitoring the test specimens. Similarly, a larger rectangular block is made in between the openings as shown in Fig. 4, to

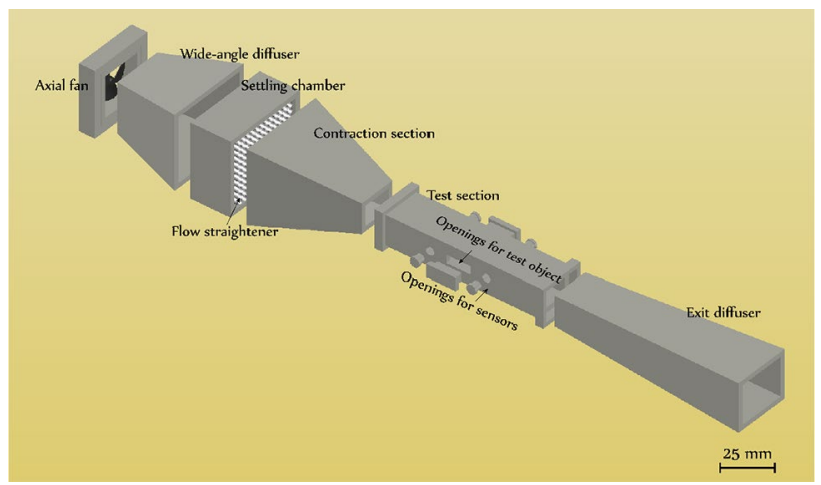

Fig. 4 CAD 3D model of mini wind tunnel

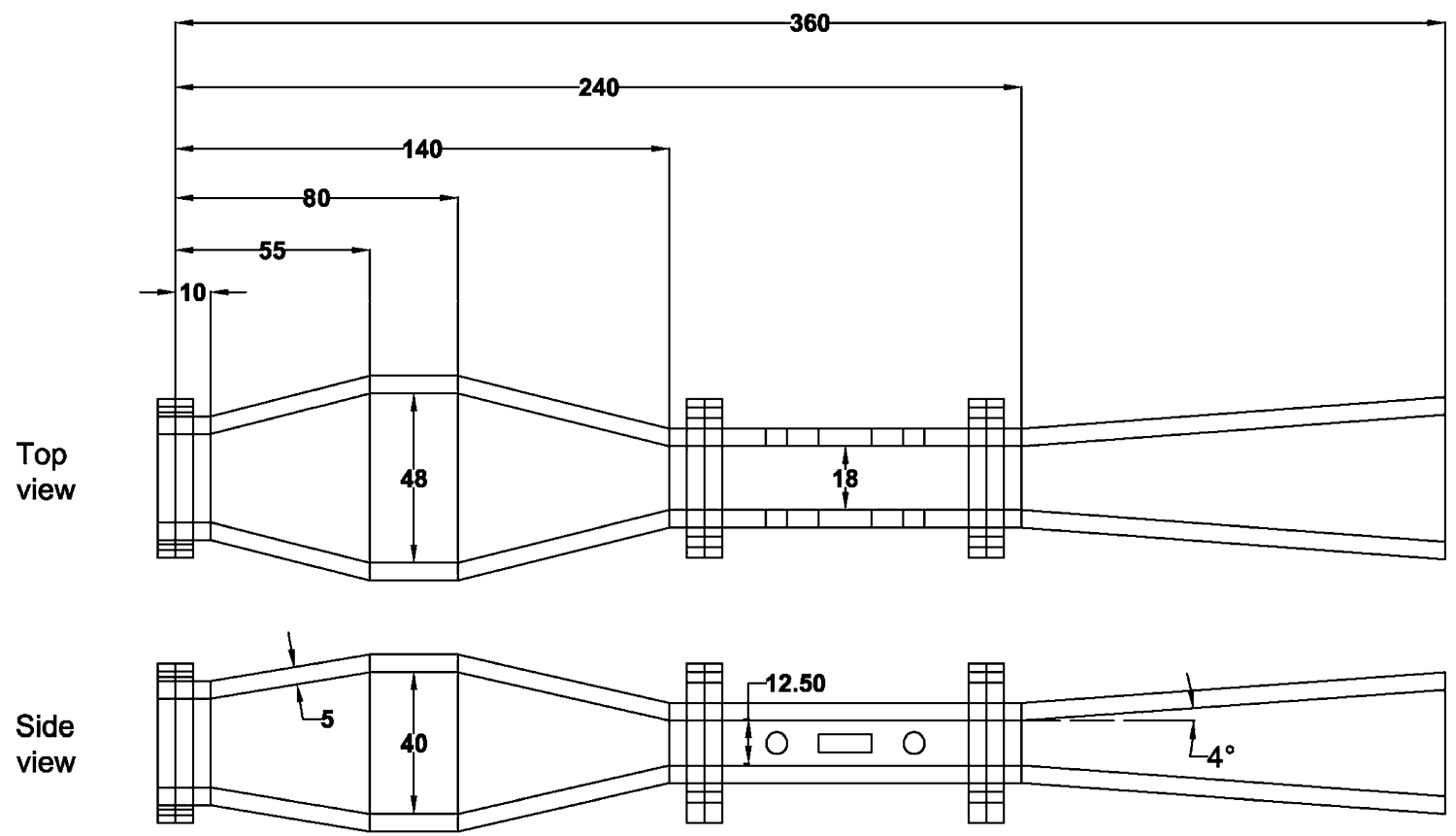

All dimensions are in $\mathrm{mm}$

Fig. 3 Mini wind tunnel dimensions 
insert microstructures. The size of the rectangular block is 5 by $15 \mathrm{~mm}$, which gives enough room to operate for models in the microscale. The wind tunnel altogether is $360 \mathrm{~mm}$ in length, which is considered a small-scale wind tunnel. The two brackets at the test section allow adjusting different cross sections and provide access to clean inside. The bracket at the inlet of the tunnel is connected to the wide-angle diffuser, which permits interchangeable fans to achieve different Reynolds number.

Wind tunnel fabrication can be done in many different methods. The choice of material is acrylic sheet due to its transparent property and smoothness. The transparency allows flow visualization, and the minimum roughness does not hinder the flow path to achieve laminar flow. A laser machine is used to cut 5.6-mm-thick acrylic sheet. It is important to choose a thick enough material to have a better handling during assembly. Each section of the wind tunnel is made from four pieces of acrylic sheets that are glued together using dichloromethane $\left(\mathrm{CH}_{2} \mathrm{C}_{12}\right)$ to create the specified geometries. The $\mathrm{CH}_{2} \mathrm{C}_{12}$ is an adhesive for plastic material, and it bonds within seconds of application of the product.

Once each section is successfully glued together, brackets are glued at both ends of the test sections. The brackets are bonded since modularity is important in the miniature wind tunnel design. The brackets allow removing and implementation of different test sections. A similar bracket is placed at the inlet in order to change fans to get a wide spectrum of airflows. Other connections that are tapered such as the contraction, wide-angle diffuser and exit diffuser are rounded and smoothed in order to assemble properly. Lastly, Fig. 5 is the built mini modular wind tunnel

\section{Analysis of losses in wind tunnel}

To determine the total pressure loss in the wind tunnel, it is important to understand the losses in each component of the wind tunnel. The loss coefficient $K$ is found

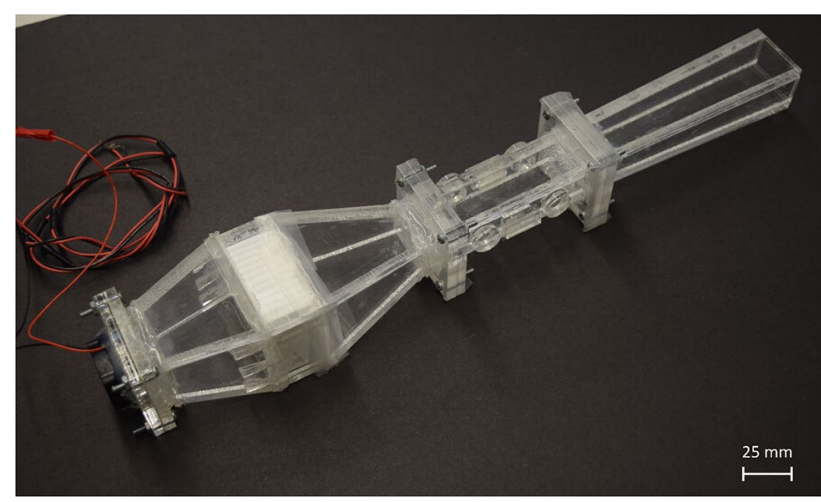

Fig. 5 Final assembly of mini wind tunnel using engineering design rules. The equations and graphs that determine the losses of each section originate from large wind tunnel designs, as there are very few artifacts on design rules for mini wind tunnel. Once the $K$ value is determined, the pressure drop from the inlet to outlet is found by using the fundamental fluid dynamic Eq. (5) [7]:

$p_{i}=\frac{K_{i} \times \rho_{a} \times v_{\mathrm{avg}, i}^{2}}{2}$

Friction loss coefficient $(f)$, length of the certain section $(L)$ and diameter of the section $(D)$ is grouped together as $(f L / D)$, loss coefficient of section $K i$. Subscript ' $i$ ' denotes the values of the particular section. $p_{i}$ is the pressure, $v_{\text {avg, } i}$ is average velocity of the air in section named ' $i$ ' and $\rho_{\text {air }}$ is the density of air at $25^{\circ} \mathrm{C}$.

\subsection{Test section loss coefficient}

The losses in the test sections are along the straight length. The loss coefficient for a long straight section compared to those for the other components of the wind tunnel is given in Eq. (6) [7]:

$K_{\mathrm{TS}}=\frac{f_{\mathrm{TS}} \times L_{\mathrm{TS}}}{D_{\mathrm{TS}}}$

The parameter $f$ is defined as the friction coefficient $f_{\mathrm{TS}}=\frac{64}{R e}$ which is only defined for laminar flow, $\left(L_{\mathrm{TS}}\right)$ the length of the test section is $100 \mathrm{~mm}$ and the equivalent hydraulic diameter $\left(D_{\mathrm{TS}}\right)$ is $14.75 \mathrm{~mm}$. The loss coefficient of the test section is 0.29 . The pressure drop in the test section is estimated as $0.45 \mathrm{~Pa}$ using a velocity of $1.59 \mathrm{~m} / \mathrm{s}$ for a Reynolds number of 1500 .

\subsection{Contraction loss coefficient}

To determine the losses in the contraction section the following equation is applied [9]:

$K_{\mathrm{CS}}=\frac{0.32 \times f_{\mathrm{av}} \times L_{\mathrm{CS}}}{D_{\mathrm{ex}}}$

The average friction coefficient, $f_{\mathrm{av}}$ is found from the mean of the friction coefficient on both sides of the contraction section.

$f_{\mathrm{av}}=\left\{\left(\frac{1}{2}\right)\left(\frac{64}{\operatorname{Re}_{\text {inlet }}}+\frac{64}{\operatorname{Re}_{\text {outlet }}}\right)\right\}$

The equivalent exit diameter $\left(D_{\mathrm{ex}}\right)$ is $14.75 \mathrm{~mm}$ which is for the cross section leading into the test chamber of $18 \times 12.5 \mathrm{~mm}$. The loss coefficient for the contraction section is 0.3031 , and the corresponding pressure drop

SN Applied Sciences 
across the contraction section is 0.4675 Pa estimated using Eq. (4).

\subsection{Settling chamber loss coefficient}

The settling chamber is a shortest straight section of the wind tunnel. For relatively small straight sections, the loss coefficient is [9]:

$K_{\mathrm{SC}}=\frac{0.01 \times L_{\mathrm{SC}} \times\left(a_{\mathrm{SC}}+b_{\mathrm{SC}}\right)}{a_{\mathrm{SC}} \times b_{\mathrm{SC}}}$

$a_{\mathrm{SC}}$ and $b_{\mathrm{SC}}$ are cross section dimensions of the settling chamber, $48 \times 40 \mathrm{~mm}$, and the length $L_{S C}$ is $25 \mathrm{~mm}$, (Fig. 3). The loss coefficient according to this equation is 0.01146 and the pressure drop for the settling chamber is the smallest of all sections due to it small length, which is $2.43 \times 10^{-4} \mathrm{~Pa}$

The honeycomb structure that is placed to straighten the flow also contributes to the loss in the wind tunnel. The honeycomb structure is composed of 132 straws with $3.5 \mathrm{~mm}$ diameter. The ratio of free area to the total area of the settling chamber is 0.6610 . From these values, losses at obstruction to the flow, screen loss coefficient factor, can be found from the Woods handbook [9] as $K_{\mathrm{HC}}=0.71$. The pressure associated to this loss is $1.52 \times 10^{-5} \mathrm{~Pa}$.

\subsection{Diffuser loss coefficient}

The loss coefficient of a diffuser is dependent upon the cross section of the inlet and the outlet [9] which is represented by an equivalent diameter. The equivalent diameter depends on the shape of the diffuser. There are generally four types of diffusers that determine the equivalent diameter [9].

The wide-angle diffuser chosen for the wind tunnel design has a transition from circular to rectangular cross section. The fan inlet is circular ( $25 \mathrm{~mm}$ diameter), and hence, the equivalent diameter is $25 \mathrm{~mm}$. There is a gradual expansion loss when the air from the fan enters the wide-angle diffuser. For any given diffuser a standard loss coefficient, $K=1$ should be added to the existing loss coefficient which is 0.9450 , [9], thus making the total loss coefficient for the wide-angle diffuser, $K_{\mathrm{WD}}=1.9450$ and the corresponding pressure drop of the wide-angle diffuser was found using Eq. (5), which is $P_{\mathrm{WD}}=0.000477 \mathrm{~Pa}$.

Similarly for the exit diffuser, the equivalent diameter needs to be determined to find the loss coefficient. The exit diffuser located at the end of the wind tunnel has a transition from one rectangular cross section to another. Therefore, the equivalent diameter is $14.75 \mathrm{~mm}$. The loss coefficient is determined as 0.23 [9]. Adding standard loss coefficient, the total loss contributed by the exit diffuser is $K_{E D}=1.23$. The pressure drop, using the velocity as $(0.051 \mathrm{~m} / \mathrm{s})$ in Eq. (5), of the diffuser is $P_{E D}=1.89 \mathrm{~Pa}$

\subsection{Total loss coefficient in wind tunnel}

The total loss coefficient of the wind tunnel is determined by summing the coefficient factor $\mathrm{K}$, across the system. The total loss coefficient is:

$\sum K=K_{\mathrm{TS}}+K_{\mathrm{CS}}+K_{\mathrm{SC}}+K_{\mathrm{WD}}+K_{\mathrm{ED}}+K_{\mathrm{HC}}$

The loss coefficient allows determination of the minimum power to run the wind tunnel. The second most important parameter is the total pressure drop of the wind tunnel. The total pressure drop gives an idea of the losses that are occurring in the wind tunnel and can be further compared with 3D simulation model to indicate the validity of the analytical calculations. The pressure drop in the wind tunnel due to the losses is $2.64 \mathrm{~Pa}$.

$\Delta P=P_{\mathrm{TS}}+P_{\mathrm{CS}}+P_{\mathrm{SC}}+P_{\mathrm{WD}}+P_{\mathrm{ED}}+P_{\mathrm{HC}}$

\subsection{Power supplied to wind tunnel}

The minimum power needed for the wind tunnel is determined through knowing the losses in the system. One approach is using an equation that estimates the power of the shaft to rotate the fan [10]:

$H=\left(\frac{\sum K}{\eta}\right) \times \frac{\rho_{a} \times A_{\mathrm{TS}} \times v_{\mathrm{TS}}^{2}}{2}$

where:

$H$-Shaft minimum input power

$(W) \eta=$ Efficiency of motor

The power needed to run the low-speed wind tunnel is about $1.22 \times 10^{-3}$ Watt. The efficiency of the fan motor was approximated as 0.8 . The second parameter that is noted for selection of the fan is the airflow. An axial fan is selected with maximum airflow $0.026 \mathrm{~m}^{3} / \mathrm{min}$ which corresponds to a maximum Reynolds number of 1500 .

\section{COMSOL modeling}

\subsection{Mini wind tunnel}

Flow simulation was performed on the wind tunnel to understand the behavior of the flow inside. COMSOL Multiphysics 4.2 was used to analyze the flow. Fluid was set to be laminar, incompressible and inviscid inside the 
wind tunnel. Navier-Stokes and continuity equations were used to analyze the flow parameters, namely velocity and pressure. Stationary solver was used to solve the equations. Following equations were used by the solver.

In the following, $u$ is the velocity field, $F$ is the volume force, $p$ is the fluid pressure, $\mu$ is the dynamic viscosity of the fluid, $\rho$ is the density of the fluid and $/$ is the identity or unit matrix. The effect of the gravity is neglected as the fluid considered is air.

For laminar flow:

$\rho_{\text {fluid }}\left(u_{\text {fluid }} \cdot \nabla\right) u_{\text {fluid }}=\nabla \cdot\left[-p l+\mu_{\text {fluid }}\left(\nabla u_{\text {fluid }}+\left(u_{\text {fluid }}\right)^{T}\right)\right]+F$

$\rho_{\text {fluid }} \nabla \cdot u_{\text {fluid }}=0$

The selected boundary conditions are

No slip at the wall, $u_{\text {fluid }}=u_{w}=0$

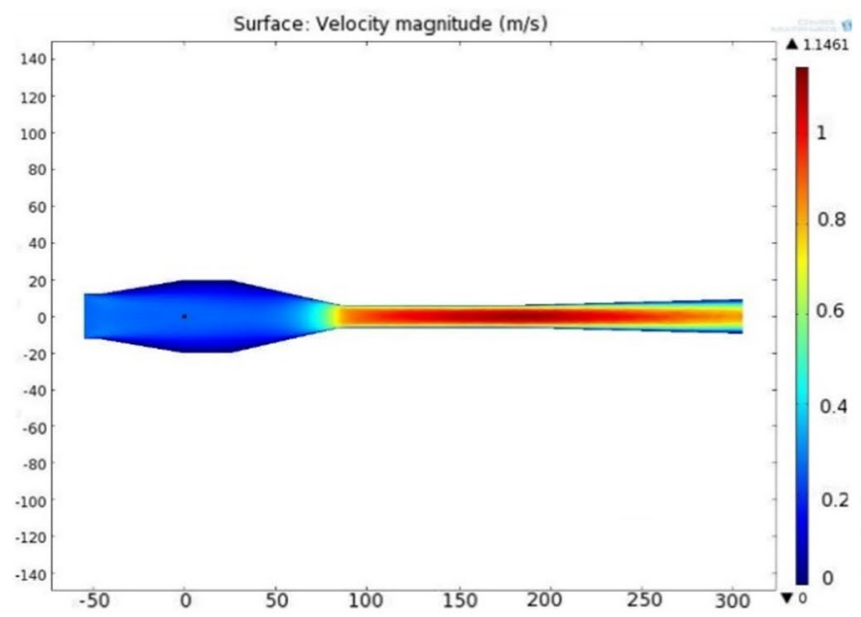

(a)

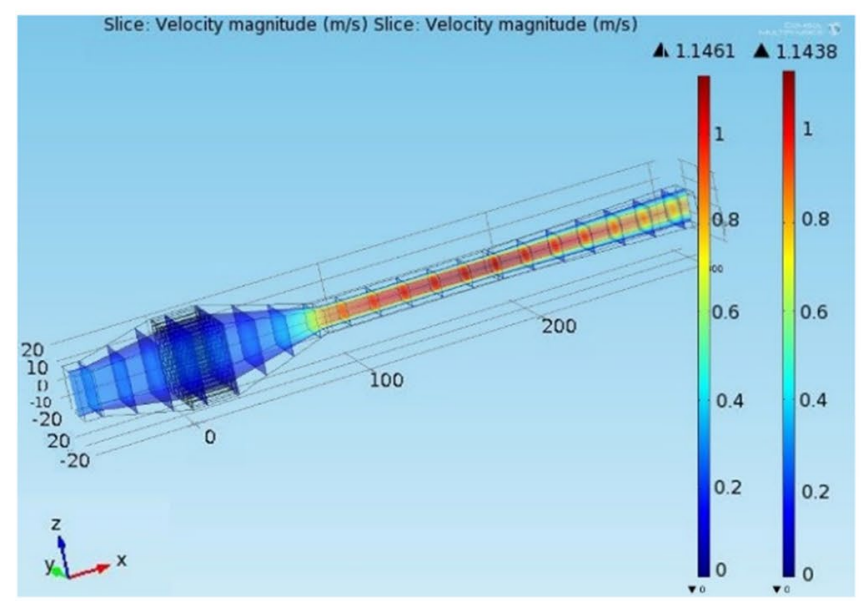

(c)
At the inlet $u_{\text {fluid }}=-U \cdot n$

At the Outlet $p=p_{o}$

The wind tunnel was sliced along the length to observe the pressure and velocity distribution along the length. The cut section is illustrated by Fig. 6 . The honeycomb structure was also sliced to understand the behavior of velocity inside the honeycomb which is represented in Fig. 6.

The simulations were carried out for the minimum flowrates of $160 \mathrm{ml} / \mathrm{s}$, and the observations were made for the velocity variations. $A 2 D$ representation of velocity and pressure distribution along the length of the mini wind tunnel is shown in Fig. $6 a$ and b. The pressure is the highest at the inlet of the wind tunnel, decreasing as the flow passes through honeycomb structure and at the inlet to the test section. A 3D visualization of transverse velocity distribution is shown in Fig. 6c. The velocity distribution

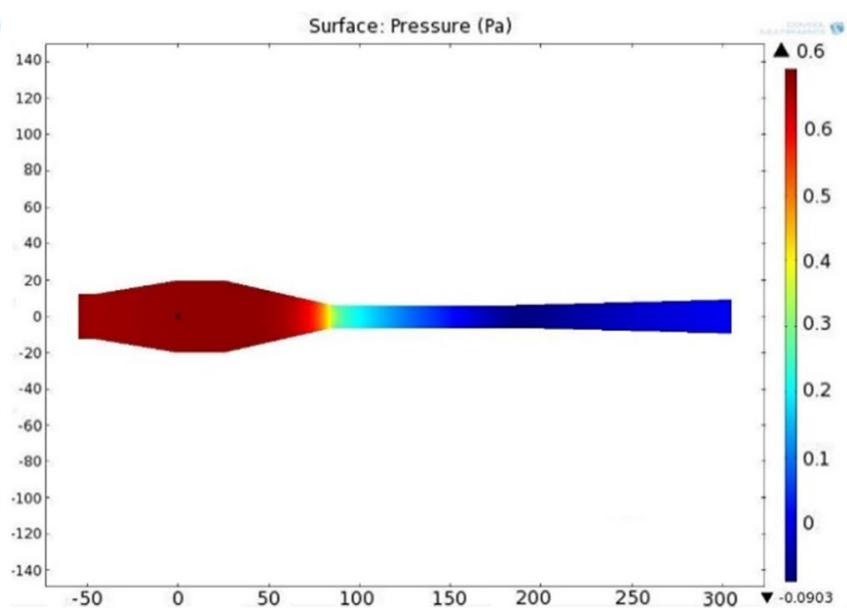

(b)

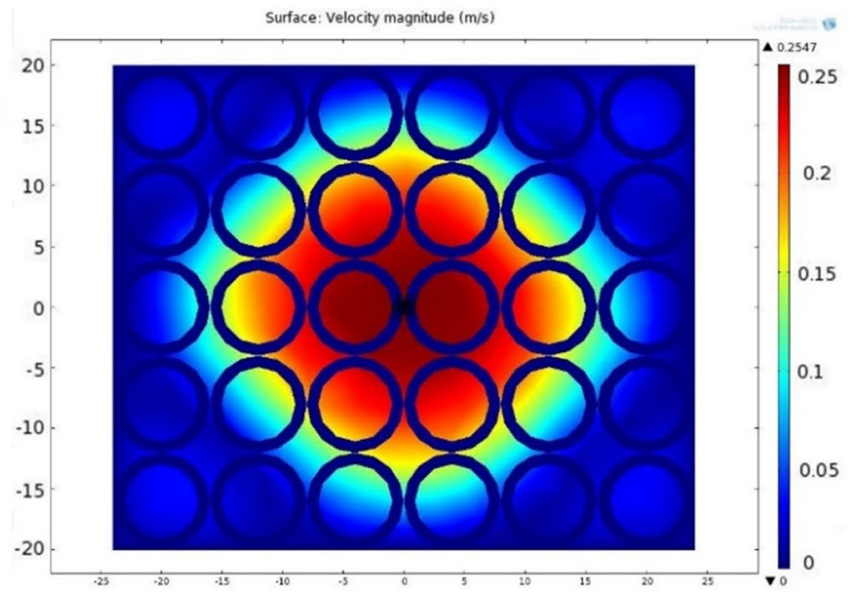

(d)

Fig. 6 a Velocity, b pressure profile along the wind tunnel for the flowrate $160 \mathrm{ml} / \mathrm{s}$. c 3D representation of velocity profile. d Velocity profile through honeycomb structure 
along the transverse direction at the cut section of the honeycomb structure is shown in Fig. $6 \mathrm{~d}$.

\subsection{Cantilever simulation setup}

COMSOL 4.2 Multiphysics was used to simulate the test section as the channel and the microcantilever as the solid structure in between, as shown in Fig. 7. The physical model used was fluid-structure interaction (FSI) that describes the behavior of the cantilever subjected to fluid flow, as shown in Fig. 7. The dimension of the test section is given in Fig. 3. In FSI physical model, an arbitrary Lagrangian-Eulerian (ALE) method was used to capture the deflection of the cantilever. While Lagrangian describes the solid mechanics of the cantilever, Eulerian describes the fluid flow through test section. The cantilever is set to include the inertia term for transient behavior.
At the outlet, a laminar flow is set with an exit pressure of zero and exit length of $0.12 \mathrm{~m}$, which represents the length of the exit diffuser. The boundary condition that is applied to the cantilever is fixed constraint on the side wall of the channel. The linear elastic model is chosen to simulate the behavior of the PDMS cantilever with Young's modulus of $802 \mathrm{kPa}$, Poisson ratio of 0.45 and density of $965 \mathrm{~kg} / \mathrm{m}^{3}$ [14].

\subsection{Experimental method}

\subsubsection{Mini wind tunnel}

The mini wind tunnel that was designed and built is shown in Fig. 5 consists of an axial flow fan at the inlet, with dimension $25 \times 25 \times 10 \mathrm{~mm}$. It gives a maximum air flow of $460 \mathrm{ml} / \mathrm{s}$. The operating range of the fan is about

$\rho_{\text {fluid }} \frac{\partial u_{\text {fluid }}}{\partial t}+\rho\left(u_{\text {fluid }} \cdot \nabla\right) u_{\text {fluid }}=\nabla \cdot\left[-p l+\mu_{\text {fluid }}\left(\nabla u_{\text {fluid }}+\left(\nabla u_{\text {fluid }}\right)^{T}\right)\right]+F$

$\rho_{\text {fluid }} \nabla \cdot u_{\text {fluid }}=0$

$\rho_{\text {fluid }} \frac{\partial^{2} u_{\text {solid }}}{\partial t^{2}}-\nabla \cdot \sigma=F \cdot u$

Since the pressure losses in the wind tunnel are small compared to the fan pressure, they are not taken into consideration in the simulation. Pressure at the inlet is determined at different flowrates using Eq. (19)

$p_{\text {In }}=p_{\text {Ref }} \times\left(\frac{\mathrm{RPM}_{\mathrm{Ref}}}{\mathrm{RPM}_{\mathrm{ln}}}\right)^{2}$
3-6.8 V. Flowrates given by the fan can be controlled by the input voltage given to the fan. Fan RPM, Reynolds Number (Re) and flowrate $(Q)$ were measured for different Fan voltage $\left(V_{f}\right)$. Each property has linear relationship with Fan voltage as shown in Fig. 8a-c. Calibration of fan voltage, fan RPM, flowrate (Q) and Reynolds number within test section were calculated and presented as function of fan voltage. To perform RPM calibration, small reflective tape is attached to one of the fan blade, and RPM was noted using a tachometer for voltage from 2.75 to $5 \mathrm{~V}$ with increment of $0.25 \mathrm{~V}$. Flowrate of the wind tunnel was measured using a flow sensor (FLR1005 Omega sensor). Flow sensor was kept at the downstream of exit diffuser, and the readings were taken for voltage from 2.75 to $5 \mathrm{~V}$ with
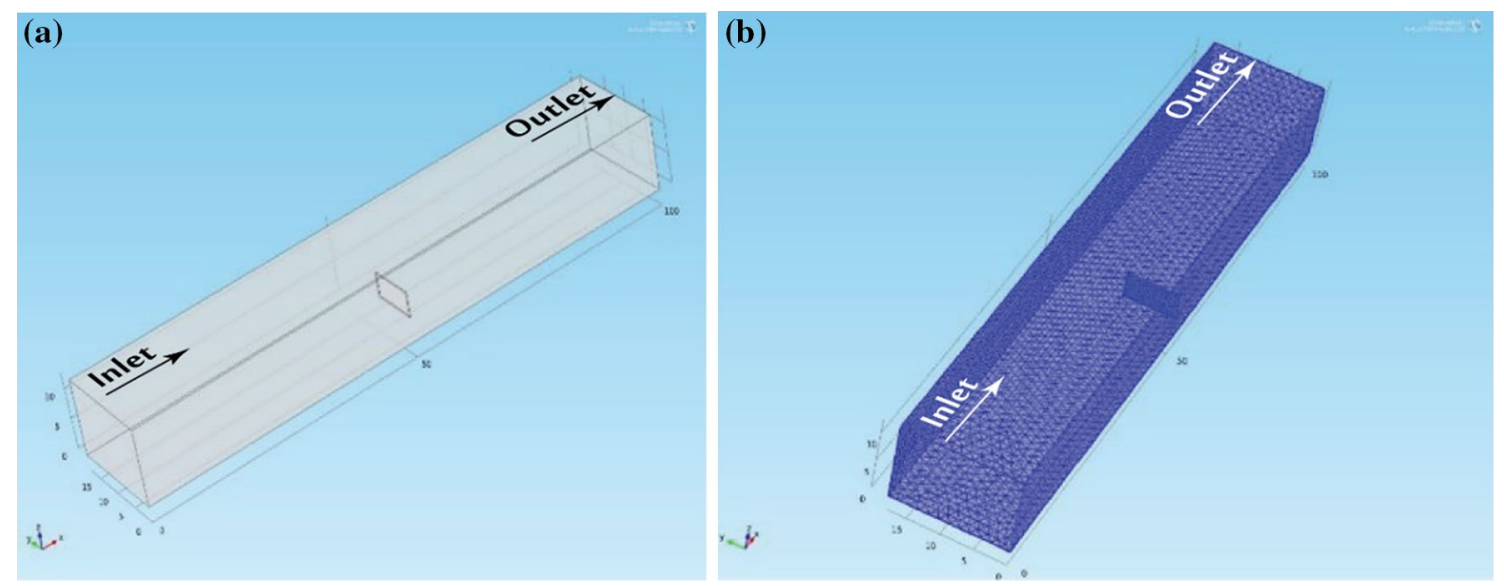

Fig. 7 Microcantilever simulation setup a Without mesh $\mathbf{b}$ With mesh 


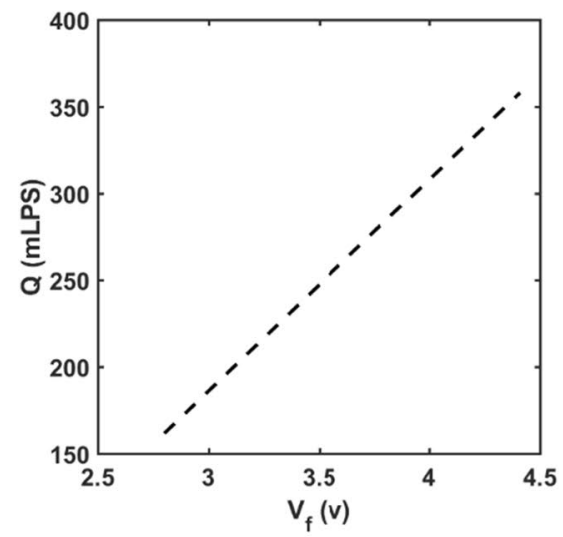

(a)

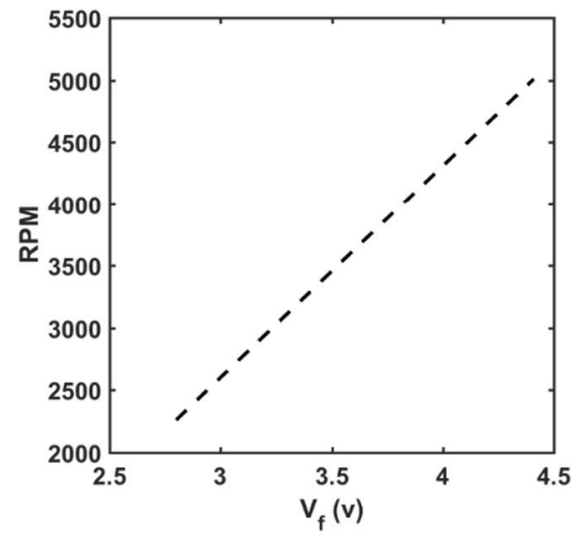

(b)

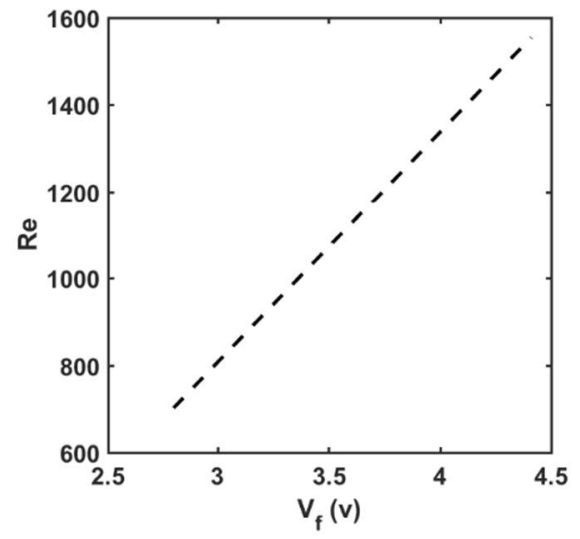

(c)

Fig. 8 a Flowrate $(Q)$, b Fan RPM and $\mathbf{c}$ Reynolds number $(\mathrm{Re})$ as the function of Fan voltage $\left(v_{\mathrm{f}}\right)$

increment of $0.25 \mathrm{~V}$. Reynolds number corresponding to each fan voltage was calculated using Eq. (1). Velocity data were obtained from corresponding flowrate by using the relation $v_{\text {avg }}=Q / A_{\mathrm{TS}}$, where $A_{\mathrm{TS}}$ is cross-sectional area of the test section. To confirm that the test section receives a laminar streamlined input, a smoke test was carried out. The smoke test consists of sending dry ice smoke streams into the wind tunnel. The first four images are focusing in the test section, where the flow must have straight streamlines. The smoke streaks are straight which characterizes laminar flow. Figure 9a corresponds to when airflow in the wind tunnel is absent. Figure $9 b-d$ shows the streamlines for Reynolds numbers of 650,800 and 1500, respectively.

\subsubsection{Microcantilever study in wind tunnel}

The mini wind tunnel was tested by performing experiments with microcantilever shown in Fig. 10. Microcantilevers were fabricated to perform deflection experiments in the wind tunnel. The microcantilevers were made of polydimethylsiloxane (PDMS). Ratio of 10:1 of base to curing agent is used to achieve the desired material property [14]. Once the base was mixed with the curing agent, it was placed in a vacuum seal container to get rid of any bubbles during mixing. Then the mixture was spin coated. The RPM of spin coating machine was tuned to get the layer thickness of $240 \mu \mathrm{m}$.

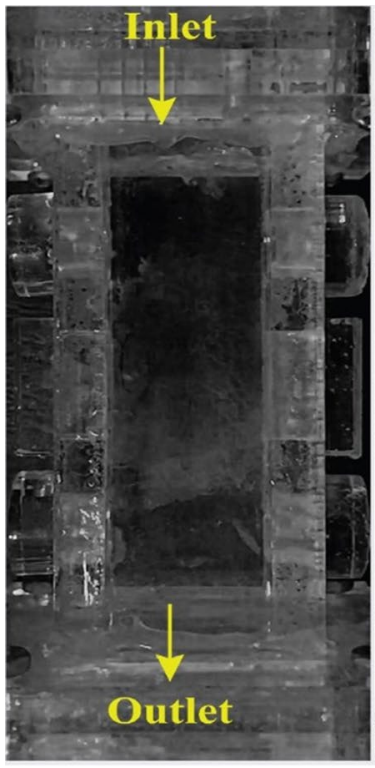

(a)

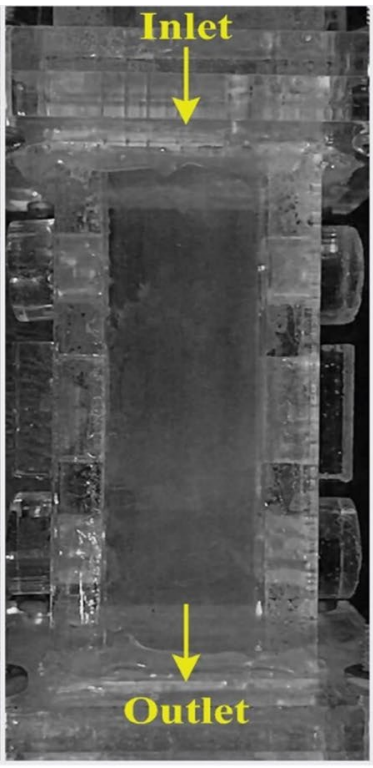

(b)

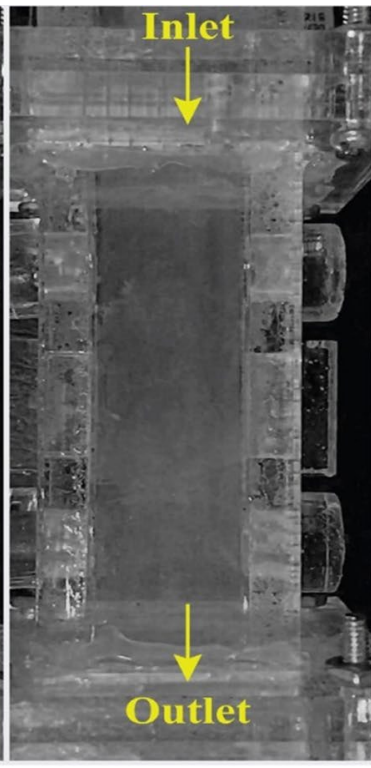

(c)

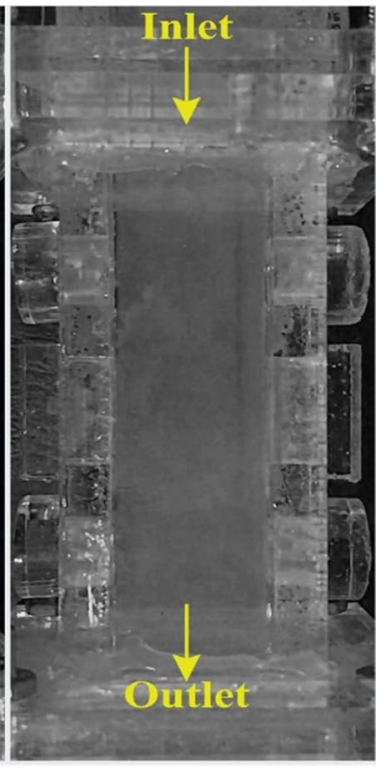

(b)

Fig. 9 Streamlines in mini wind tunnel for Reynolds number a 0, b 650, c 800 and d 1500 


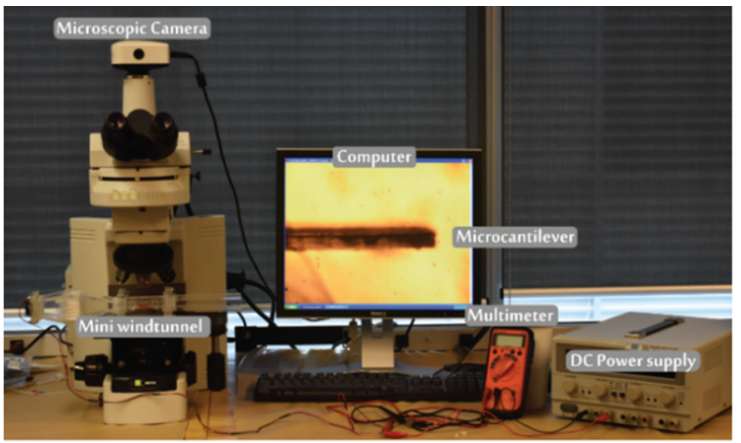

(a)

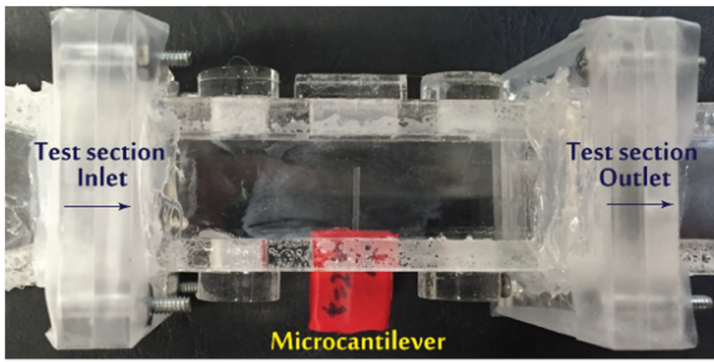

(b)

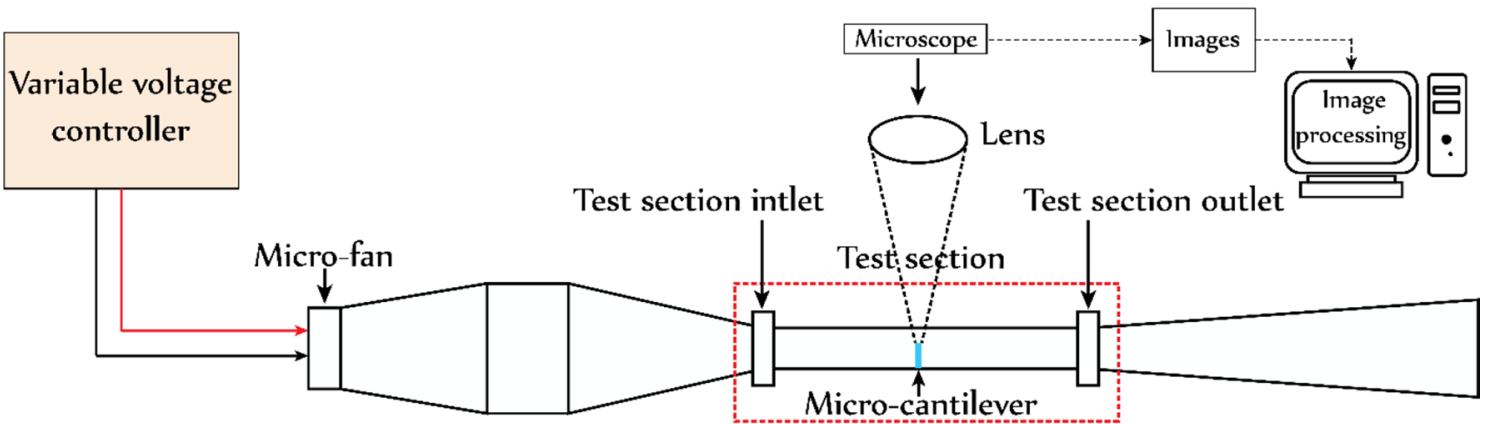

(c)

Fig. 10 a Experimental setup, b microcantilever inside test section, c schematic of the experimental setup

After spin coat process, the thin layer is baked for $2 \mathrm{~h}$ at $60^{\circ} \mathrm{C}$. Once the curing of PDMS was complete it was carefully cut into the microcantilever beam dimensions. And finally, the cantilever was plasma bonded to its base. The Microcantilevers were inserted inside the wind tunnel to determine the deflection at different air flowrates. The microcantilever was placed at the midway of the test section, from the side wall of the wind tunnel, where it undergoes deflection due to the airflow interaction. The cantilever deflection was recorded using the optical microscope attached with a camera as shown in Fig. 10a and b shows the microcantilever beam placed inside the test section. Figure 10c shows the schematic of experimental setup. The dimension of the test section is $100 \mathrm{~mm}$ in length, $18 \mathrm{~mm}$ in width and $12.5 \mathrm{~mm}$ in depth. The advantage of having a honeycomb structure in the wind tunnel can be easily investigated when the microcantilever is studied. The graph below shows the importance of the honeycomb filter in the settling chamber. The honeycomb structure reduces turbulence and helps to steady the flow that is seen easily through the deflection of the cantilever. Figure $11 \mathrm{~d}$ shows that there is a variation in the flow in the wind tunnel before installing honeycomb screen, whereas in Fig. 11e the flow is steady with the honeycomb in place. Thus presence of honeycomb screen is really important.

\subsection{Testing of air flow}

Experimental measurements of deflection of the cantilever $(3 \times 8 \times 0.240 \mathrm{~mm})$ show good agreement with the simulated values over the entire range of flowrates in Fig. 12. This experiment was extended to study the air flow sensing using different microcantilevers. For this study, ten cantilevers were used to measure the deflection. The deflection of the microcantilever was tested for flowrates in the range of $160-360 \mathrm{ml} / \mathrm{s}$. The dimensions of cantilevers used are listed in Table 1. The difference between experimental and simulated deflections for different cantilevers was about $10 \%$ and shows that the simulation model can be used for further investigation to see the cantilever deflection. Model used for the simulation considers the input as steady laminar flow. It does not consider the vibrational effect of the fan hence the simulated results are underestimated

All the cantilevers were tested, using the COMSOL simulation to validate the experimental results. (Figure 12)

From the experiments, we obtain the variation of tip deflection against flowrates; Fig. 13 shows that the tip deflection increases with the length of the cantilever. The influence of the length of the microcantilever over the tip deflection is more as compared to that of width. 


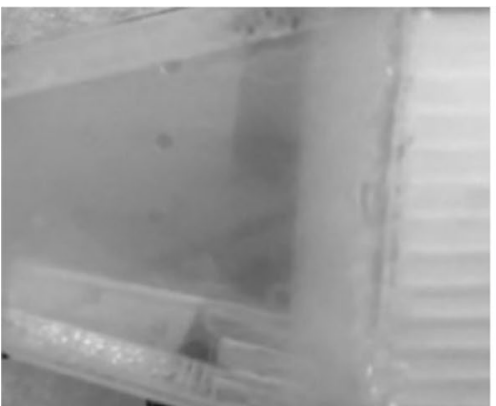

(a)

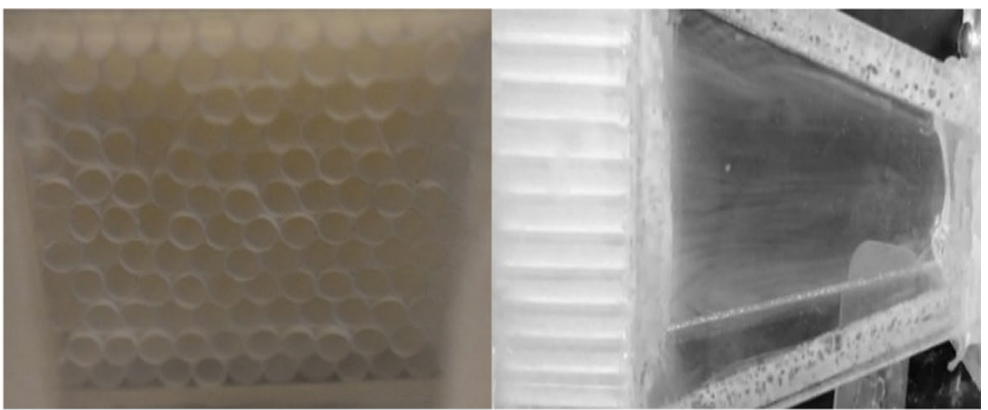

(b) (c)

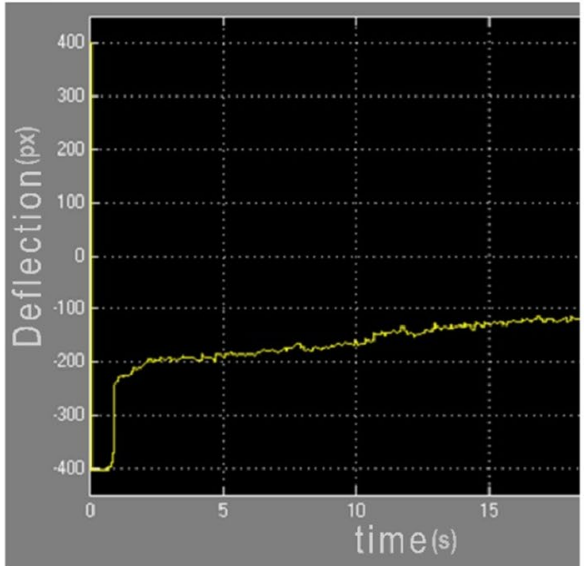

(e)

Fig. 11 a Wide-angle diffuser section, b honeycomb arrangement (flow straightener), c contraction section, $\mathbf{d}$ tip deflection without honeycomb structure, e tip deflection with honeycomb structure

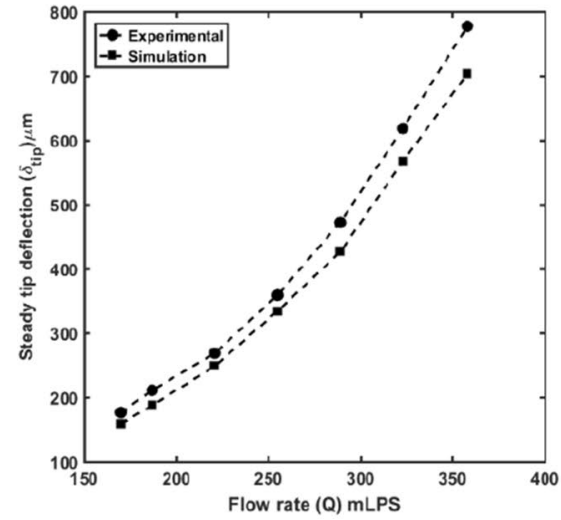

(a)

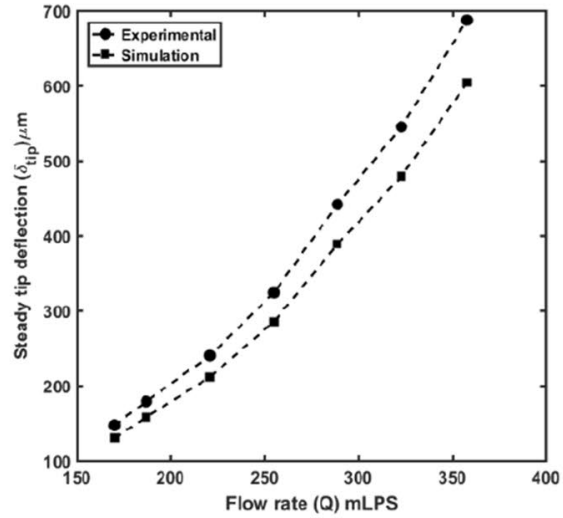

(b)

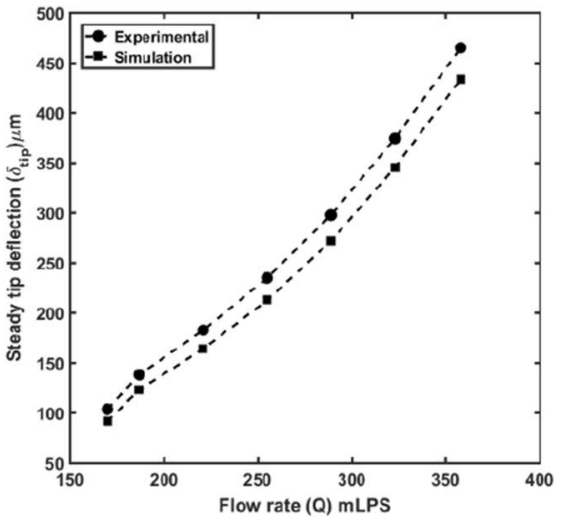

(c)

Fig. 12 Comparison of experimental and simulation results for a C1, b C4 and c C7

The microcantilever is under uniformly distributed fluid loading, and maximum deflection is observed at the free end (tip). The stiffness of the microcantilever beam at the free end is given by Eq. (20) [15]. $k_{\mathrm{sp}}=\frac{8 E i}{l_{\mathrm{b}}^{3}}$

where $k_{\mathrm{sp}}$ is the force per unit deflection at the tip of the cantilever beam, $E$ is the modulus of elasticity of the beam 
Table 1 Cantilever name and dimensions

\begin{tabular}{ll}
\hline Name & $\begin{array}{l}\text { Beam dimensions } \\
\text { (Width } \times \text { Length } \times \text { Thick- } \\
\text { ness })(\mathrm{mm})\end{array}$ \\
\hline C1 & $3 \times 08 \times 0.24$ \\
C2 & $3 \times 10 \times 0.24$ \\
C3 & $3 \times 12 \times 0.24$ \\
C4 & $4 \times 08 \times 0.24$ \\
C5 & $4 \times 10 \times 0.24$ \\
C6 & $4 \times 12 \times 0.24$ \\
C7 & $5 \times 08 \times 0.24$ \\
C8 & $5 \times 10 \times 0.24$ \\
C9 & $4 \times 10 \times 0.16$ \\
C10 & $5 \times 10 \times 0.16$ \\
\hline
\end{tabular}

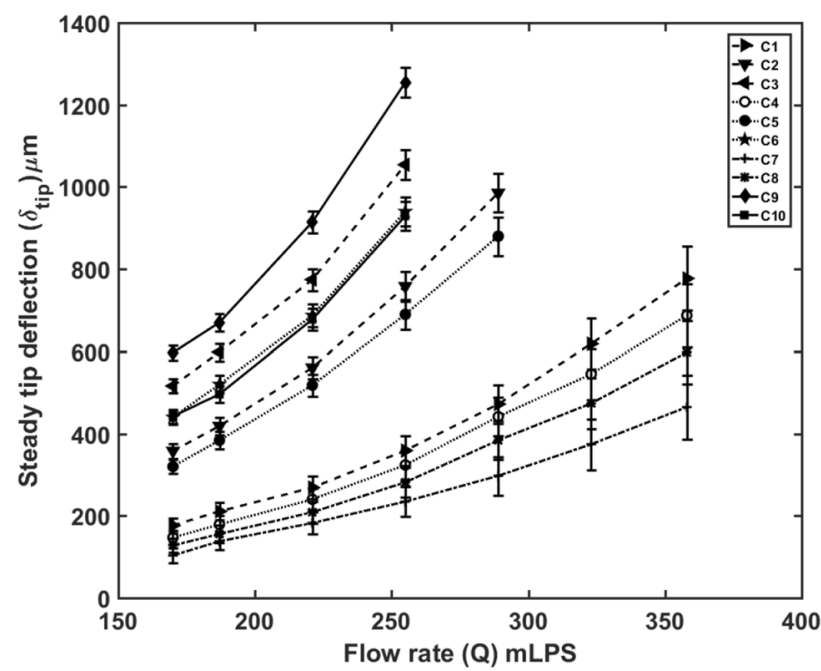

Fig. 13 Tip deflection as the function of flowrate material, $i$ is the area moment of inertia about the neutral axis of the beam cross section, and $l_{b}$ is the length of the beam. Therefore, as the length of the cantilever increases, stiffness decreases which causes more deflection in the microcantilever beam when subjected to air flow. To study the effect of length, width and thickness of the cantilever over deflection, study was grouped as following:

(a) Variation of length with constant width and thickness

(b) Variation of width with constant length and thickness

(c) Variation of thickness with constant length and width

\subsubsection{Effect of length on deflection}

Equation (21) suggests that the beam length $L_{b}$ has strong influence on beam tip deflection as $k_{\mathrm{sp}} \propto l_{\mathrm{b}}^{-3}$. Hence, the effect of beam length over tip deflection was studied using microcantilever beam with length $8 \mathrm{~mm}, 10 \mathrm{~mm}$ and $12 \mathrm{~mm}$. The study of deflection of cantilevers based on variable length yielded the results that as the length of the cantilever increases, the deflection increases. It is true for the entire range of flow. At higher flowrate the deflection is huge, and the experiment is limited to maximum deflection of $1200 \mu \mathrm{m}$ and the corresponding flowrate is $250 \mathrm{ml} / \mathrm{s}$ (Fig. 14a).

\subsubsection{Effect of width on deflection}

Effect of beam width on steady tip deflection was studied by examining the deflection of microcantilever beam with of $3 \mathrm{~mm}, 4 \mathrm{~mm}$ and $5 \mathrm{~mm}$. Constant length and thickness of $8 \mathrm{~mm}$ and $0.24 \mathrm{~mm}$, respectively, were chosen to study the effect of width because it is possible to examine the deflection of these cantilevers over the entire range of the

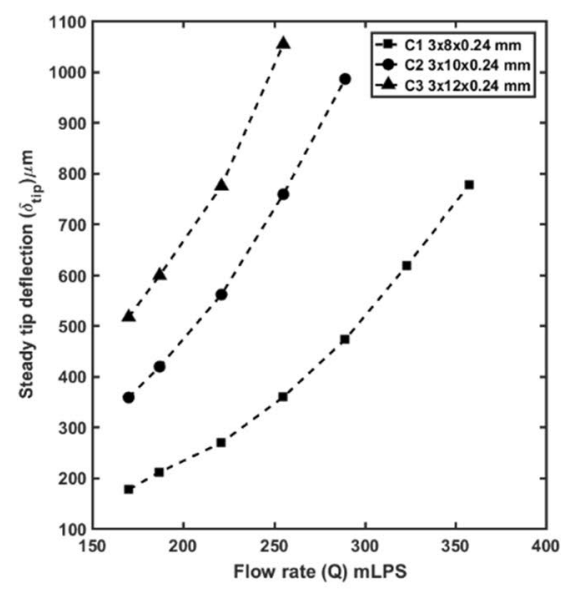

(a)

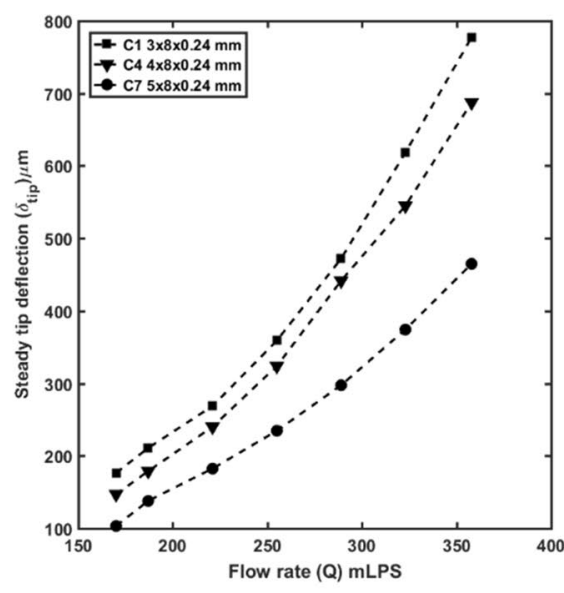

(b)

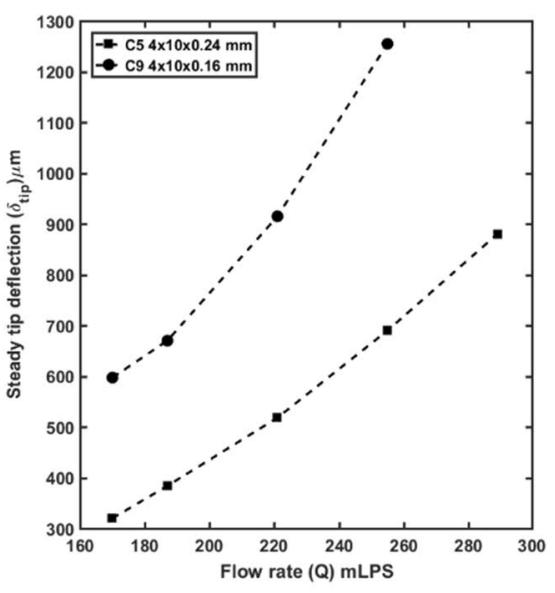

(c)

Fig. 14 Effect of $\mathbf{a}$ Length, $\mathbf{b}$ width and $\mathbf{c}$ thickness of a microcantilever over tip deflection 
flowrates. The maximum deflection can be observed for cantilever $\mathrm{C} 1$, which is the narrowest beam, $800 \mu \mathrm{m}$ for the maximum flowrate of $360 \mathrm{ml} / \mathrm{s}$. This observation is consistent for entire flow range. From Fig. 14b, it can be observed that as the width of the cantilevers increase, the deflection decreases. Because the moment of inertia in Eq. (21) calculated as, $i=\left(\frac{w_{\mathrm{b}} t h_{\mathrm{b}}^{3}}{12}\right), w_{\mathrm{b}}$ and $t h_{\mathrm{b}}$ are beam width and thickness respectively. Hence, stiffness of the cantilever is directly proportional to its width. Thus, wider cantilever offers relatively more resistance to the deflection.

\subsubsection{Effect of thickness on deflection}

As the thickness of the cantilever is reduced, it is observed that the thinner cantilever deflects more. However, because the deflection remains in the range of 400-1200 $\mu \mathrm{m}$, thinner cantilevers provide better visualization of flowrates between 160 and $250 \mathrm{ml} / \mathrm{s}$ (lower flowrates) (Fig. 14c). Cantilever C9 is highly sensitive to deflection in this flow range which makes it easier to visualize under the microscope.

\section{Conclusions}

An open-loop low-speed mini wind tunnel is designed and built to study the fluid interaction of microstructure after examining various potential designs. The proposed mini wind tunnel has total size of $460 \times 48 \times 40 \mathrm{~mm}$ with laminar flow inside the test section $(\operatorname{Re}<1500)$. Based on the maximum size of the object to be tested inside the mini wind tunnel, the dimensions of test section were finalized. Remaining parts were designed so that they complement test section design. Laminar flow simulation was conducted for the whole wind tunnel to understand the behavior of the flow inside the wind tunnel. Flow behavior is found to be satisfactory for testing microstructures. Smoke tests ensured the flow inside the test section is streamline flow. Later, fluid microstructure interaction study was conducted using the designed mini wind tunnel. FSI module in COMSOL Multiphysics is used. The steady tip deflection of microcantilever of various aspect ratios was examined. Steady tip deflection of microcantilever was studied for flowrates up to $430 \mathrm{ml} / \mathrm{s}$. The influence of beam length, width and thickness over tip deflection was experimentally studied by varying length between 8 and $12 \mathrm{~mm}$, width between 3 and $5 \mathrm{~mm}$ and thickness between 0.24 and $0.16 \mathrm{~mm}$. The results suggested that the length of the microcantilever is strong contributor to beam stiffness. Experimentally, the tip deflection is investigated using PDMS microcantilevers which were fabricated using spin coating technique. Obtained results were compared with simulated results. Simulation and experimental results are in good agreement. Thus, the designed mini wind tunnel can be used for testing fluid interaction of any new microstructure.

Acknowledgements The financial supports from NSERC and CuRC research Grants of M. Packirisamy and NSERC Grant of R. B Bhat are acknowledged.

\section{Compliance with ethical standards}

Conflict of interests The authors declare that they have no conflict of interests.

\section{References}

1. Kuo CY, Tzeng CT, Ho MC, Lai CM (2015) Wind tunnel studies of a pedestrian-level wind environment in a street canyon between a high-rise building with a podium and low-level attached houses. Energies 8(10):10942-10957

2. Watanabe $Y$, Suzuki S, Sugihara M, Sueoka $Y$ (2002) An experimental study of paper flutter. J Fluids Struct 16(4):529-542

3. Yu L, Cheng H, Li S (2014) Study of parachute inflation process using fluid-structure interaction method. Chin J Aeronaut 27(2):272-279

4. Bastankhah $M$, Porté-Agel $F$ (2017) Wind tunnel study of the wind turbine interaction with a boundary-layer flow: upwind region, turbine performance, and wake region. Phys Fluids 29(6):065105

5. Howell R, Qin N, Edwards J, Durrani N (2010) Wind tunnel and numerical study of a small vertical axis wind turbine. Renew Energy 35(2):412-422

6. Barlow JB, Rae WH, Pope A (1999) Low-speed wind tunnel testing, 3rd edn. Wiley, Hoboken, pp 61-68

7. Young DF, Munson BR, Okiishi TH, Huebsch WW (2010) A brief introduction to fluid mechanics. Wiley, Hoboken, pp 316-396

8. Mehta RD, Bradshaw P (1979) Design rules for small low speed wind tunnels. Aeronaut J 83(827):443-453

9. Daly BB (1992) Woods practical guide to fan engineering. Woods of Colchester Ltd., Colchester, pp 88-93

10. Basak R, Mitra D, Mazumdar A (2011) Design of various components of an open circuit blower tunnel without exit diffuser. Int J Adv Sci Technol 2(6):88-93

11. Bell JH, Mehta RD (1988) Contraction design for small low-speed wind tunnels

12. Mehta RD (1979) The aerodynamic design of blower tunnels with wide-angle diffusers. Prog Aerosp Sci 18:59-120

13. Bell JH, Mehta RD (1989) Boundary-layer predictions for small low-speed contractions. AIAA J 27(3):372-374

14. Nezhad AS, Ghanbari M, Agudelo CG, Packirisamy M, Bhat RB, Geitmann A (2012) PDMS microcantilever-based flow sensor integration for lab-on-a-chip. IEEE Sens J 13(2):601-609

15. Bucciarelli LL (2009) Engineering mechanics for structures. Courier Dover Publications 2004:268

Publisher's Note Springer Nature remains neutral with regard to jurisdictional claims in published maps and institutional affiliations. 